Special issue of the 3rd International Conference on Computational and Experimental Science and Engineering (ICCESEN 2016)

\title{
Dependence of Fracture Toughness on Rolling Direction in Aluminium 7075 Alloys
}

\author{
S. İRIÇ* AND A.O. AYHAN \\ Sakarya University, Faculty of Engineering, Department of Mechanical Engineering, Sakarya, Turkey \\ Being a light metallic engineering material with low density, high specific stiffness and strength, aluminium \\ alloys are promising materials in the fields of aerospace, military and automotive industries. Consumption of \\ aluminium alloys in the forms of sheets and plates has generally increased in global markets over the past 45 \\ years. Rolling directions affect the anisotropy and mechanical properties of the aluminium alloys. In this work, \\ the plane strain fracture toughness $K_{\mathrm{IC}}$ values of 7075 aluminium alloy were measured in plates of three directions \\ and six orientations (L-T, T-L, T-S, S-T, L-S, S-L), using the standard (ASTM E399) compact tension specimens. \\ The results indicate that dependence of fracture toughness of 7075-T651 aluminium alloy on rolling direction is \\ obvious and that $K_{\mathrm{IC}}$ values of T-S and L-T orientations are the highest.
}

DOI: 10.12693/APhysPolA.132.892

PACS/topics: 46.50.+a, 62.20.Mk, 62.20.mm

\section{Introduction}

Nowadays aluminium materials are used widely in automotive industry due to their low density, high strength and thermal conductivity properties [1]. For the design of structures, it is crucial to control mechanical properties, such as fracture toughness [2-5]. Depending on material properties and manufacturing processes, fracture toughness may have directional variation, which is associated with anisotropy of the material. For some aluminium alloys, the anisotropic dependence of fracture toughness is high; the differences between values of $K_{\mathrm{IC}}$ can reach $30 \%$, depending on crack orientation.

In recent years, detailed studies in the aspects of composition, microstructure and the heat treatment process of 7075 aluminium alloy were carried out by many material scientists. However, there has been limited attention to the anisotropic aspect of fracture toughness of 7075T651 aluminium alloy plates and no study exists analyzing the reason and mechanism of anisotropy of fracture toughness of 7075-T651 aluminium alloy plates for all crack dimensions.

In order to study the anisotropy of $K_{\mathrm{IC}}$ values of 7075 T651 aluminium alloy, hot rolled thick plates were selected and $K_{\mathrm{IC}}$ values for the orientations of L-T, T-L, T-S, S-T, L-S, S-L were measured (Fig. 1).

\section{Experimental studies}

Al 7075-T651, supplied as a block $(70 \mathrm{~mm}$ plate thickness) was used in the present study. The typical chemical composition was as follows: $5.9 \mathrm{wt} . \% \mathrm{Zn}, 2.8 \mathrm{wt} . \%$. $\mathrm{Mg}, 0.19$ wt.\% Fe, 0.09 wt.\% Si, 0.02 wt.\% Ti, 1.9 wt.\% $\mathrm{Cu}, 0.03$ wt.\% Mn, 0.2 wt.\% $\mathrm{Cr}$ and the balance aluminium. The test procedure entails the investigation of

*corresponding author; e-mail: siric@sakarya.edu.tr

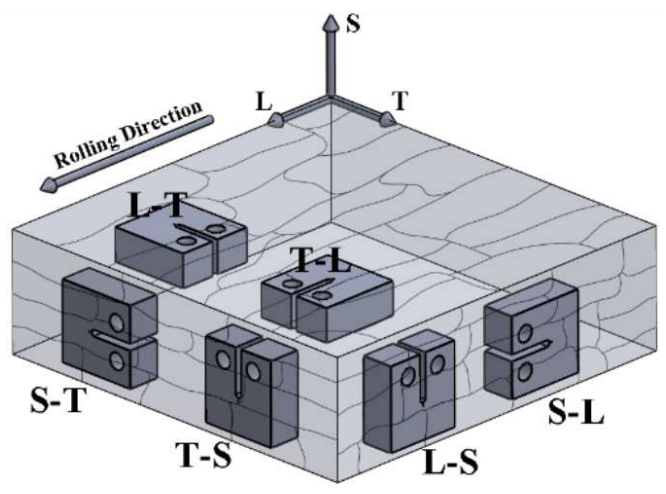

Fig. 1. Material processing directions: rolling direction (L), long transverse direction (T), shorttransverse direction $(\mathrm{S})$.

the plane strain fracture toughness $\left(K_{\mathrm{IC}}\right)$ of metals by tests using various fatigue-cracked specimens. The fracture behaviour of a material is dependent on the crack orientation and direction of crack propagation, with respect to material property axes, e.g., rolling and other directions $(\mathrm{L}, \mathrm{T}, \mathrm{S})$.

Notched and pre-cracked specimens using tensile fatigue loading were utilized as part of the test procedure. Linear elastic fracture mechanics is used to study the elastic deformation through linear stress strain relations for the entire body. Fracture toughness tests were performed according to ASTM E399 standard testing procedure using CT specimens. Figure 2 shows the dimensions of the CT specimens. All specimens were pre-cracked at $5 \mathrm{~Hz}$ with a load ratio of $0.1(\mathrm{R})$. The pre-cracking procedure fulfilled all the restrictions imposed by the standard (Fig. 2).

The crack lengths $a$ are shown in Table I and the corresponding $K_{Q}$ values were calculated using:

$$
K_{Q}=\frac{P_{Q}}{B \sqrt{W}} f\left(\frac{a}{W}\right),
$$




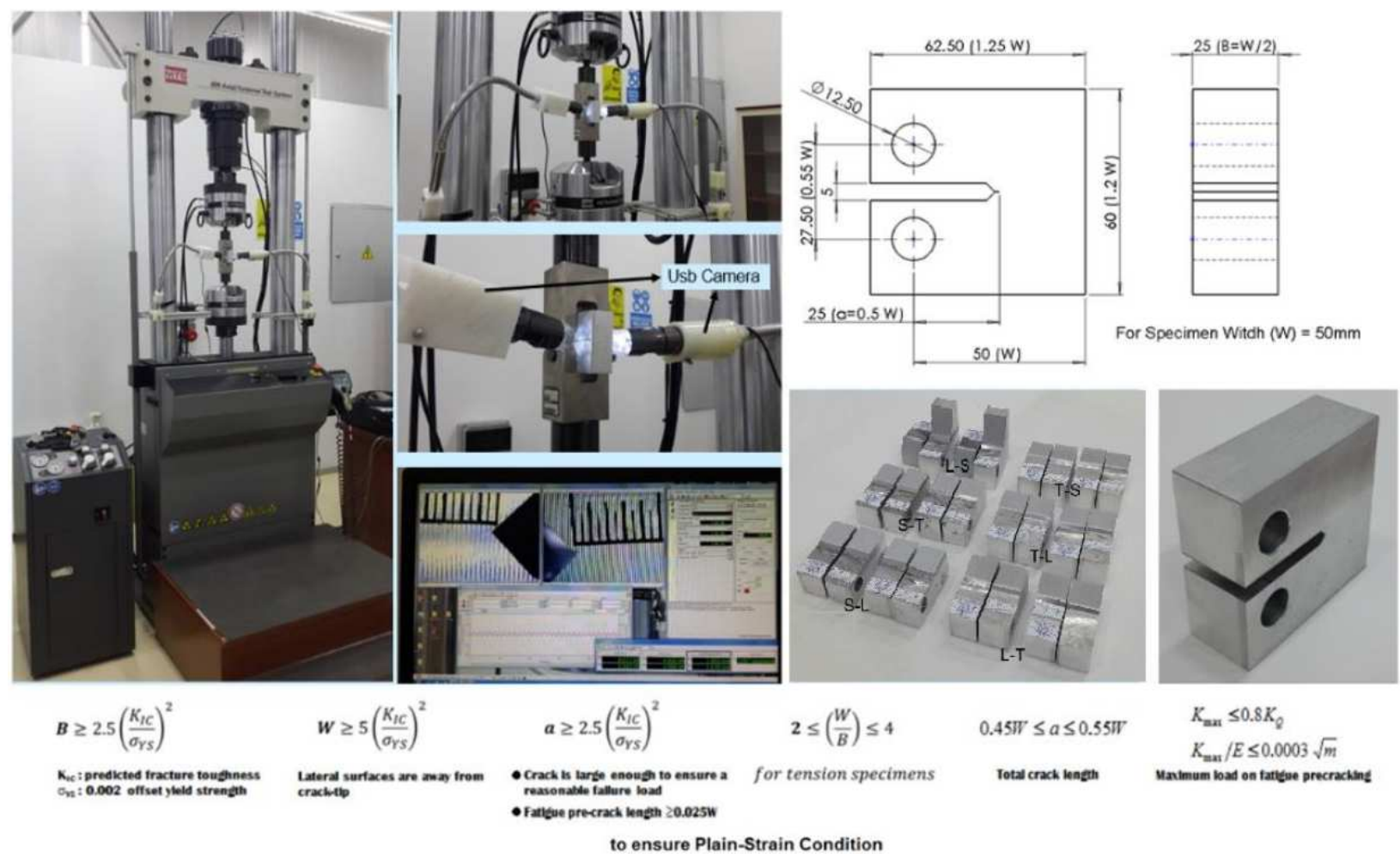

Fig. 2. Experimental setup and dimensions of specimens [4].

where

$$
\begin{aligned}
& f\left(\frac{a}{W}\right)=\frac{\left(2+\frac{a}{W}\right)}{\left(1-\frac{a}{W}\right)^{\frac{3}{2}}}\left[0.886+4.64 \frac{a}{W}-13.32\left(\frac{a}{W}\right)^{2}\right. \\
& \left.\quad+14.72\left(\frac{a}{W}\right)^{3}-5.6\left(\frac{a}{W}\right)^{4}\right] .
\end{aligned}
$$

A conditional value $P_{Q}$ is determined by drawing the secant line through the origin of the load-displacement curve with $95 \%$ of the slope of the tangent to the initial linear portion of the curve. $K_{Q}$ values, obtained, were used to compute the minimum thickness, condition for the test to meet the plane strain validity requirement, which is given by,

$$
(W-a) \geq 2.5\left(\frac{K_{Q}}{\sigma_{\mathrm{ys}}}\right),
$$

where, $B$ is thickness of the specimen, $W$ is width, $a$ is the effective crack length $\left(a_{1}+a_{2}+a_{3}\right) / 3$ and $\sigma_{\text {ys }}$ is the yield stress of the material under uniaxial tension. It was observed that all directional cases studied met the above criterion, written in Eq. (3) and hence $K_{Q}$ values were considered as plain strain linear elastic fracture toughness, $K_{\mathrm{IC}}[6]$.

\section{Results and discussion}

The plate fracture toughness values of same thickness $(25 \mathrm{~mm})$ with different orientations are distinct, and show clear directional dependency.

Fracture toughness of 7075-T651 alloy plate was studied in L-T and T-L, T-S and S-T, L-S and S-L orien- tations. A significant directional dependency of fracture toughness exists, with the fracture toughness in the T-L orientation being $25 \%$ lower than $\mathrm{L}-\mathrm{T}$ and that the $\mathrm{T}$ $\mathrm{S}$ orientation being about $25 \%$ higher than the fracture toughness in the S-T orientation [7].

\section{Conclusions}

In this study, fracture toughness of 7075-T651 alloy samples having L-T, T-L, T-S, S-T, L-S and S-L crack orientations were studied. The results show that there are considerable differences for different orientations. The fracture toughness $K_{\text {IC }}$ of 7075-T651 aluminium alloy plate has obvious anisotropy. $K_{\mathrm{IC}}$ value of the $\mathrm{L}-\mathrm{T}$ orientation is relatively higher by $7 \mathrm{MPam}^{1 / 2}$ than the T-L orientation (22 MPa m ${ }^{1 / 2}$ ). Crack propagation direction of $\mathrm{L}-\mathrm{T}$ orientation is perpendicular to the direction of rolling deformation. Cracks absorb more energy when they propagate in the L-T orientation, so the fracture toughness of L-T orientation is higher than that of the T-L orientation.

Although T-S orientation has a higher fracture toughness than L-T orientation, much thicker specimens are needed for this orientation, which makes production more difficult. Fracture toughness of L-S orientation is the highest $\left(41 \mathrm{MPam}^{1 / 2}\right)$. It should be noted that the lamellar structure of the L-S oriented specimen has characteristic splitting $\left(90^{\circ}\right.$ turn $)$ that follows the grain boundaries and the frequent directional changes of this orientation cause retardation of the master crack propagation [5]. 
TABLE I

Comparison of results.

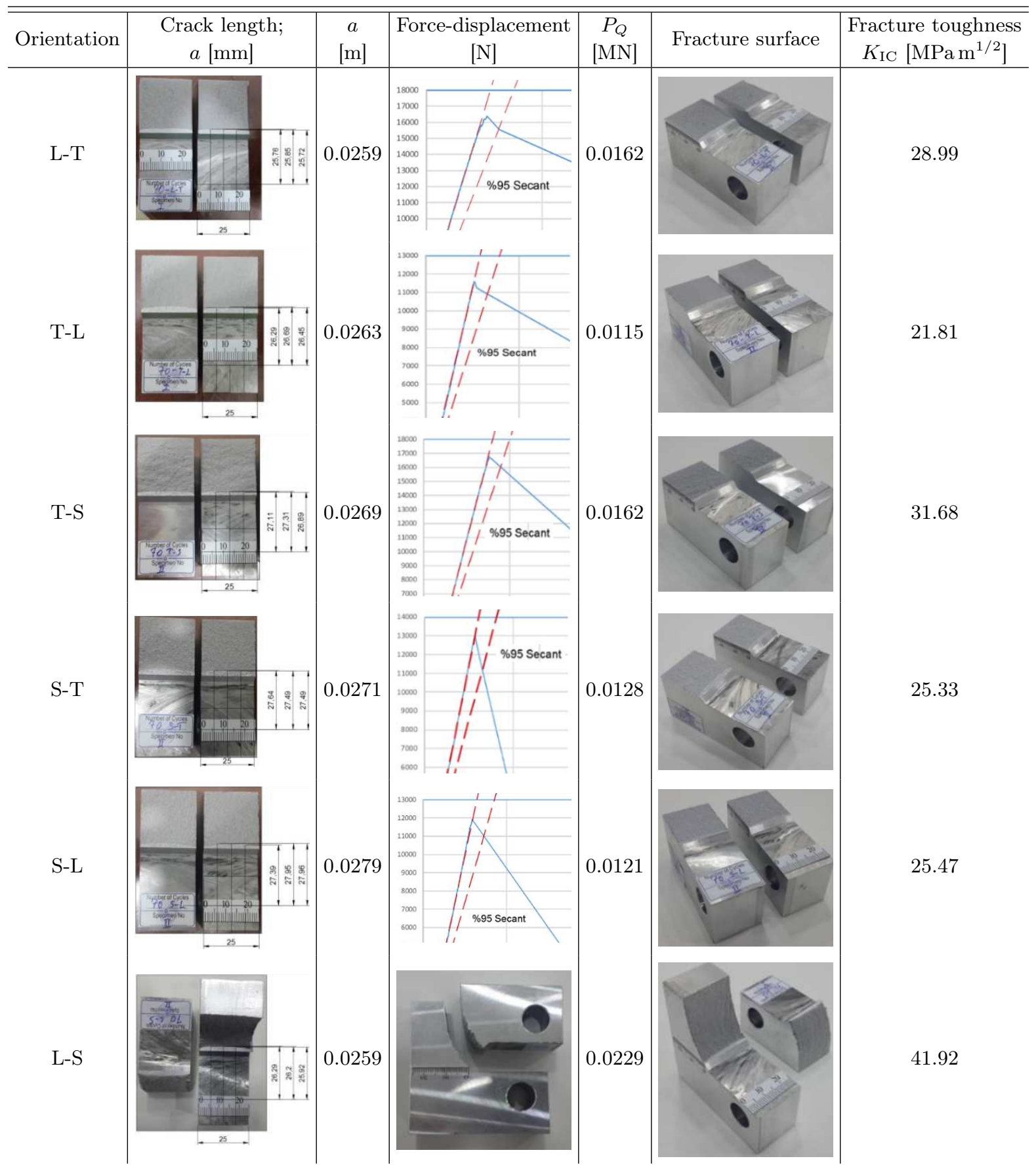

\section{Acknowledgments}

The financial support by The Scientific and Technological Research Council of Turkey (TUBITAK) of this study, under Project No: 113M407, is gratefully acknowledged.

\section{References}

[1] M. Koru, O. Serce, Acta Phys. Pol. A 130, 453 (2016).

[2] M. Tajally, E. Emadoddin, Mater. Design 32, 1594 (2011). 
[3] T.F. Morgeneyer, J. Besson, H. Proudhon, M.J. Starink, I. Sinclair, in: 12th Int. Conf. Fracture 2009 (ICF-12), NRCC, Ottawa 2009, p. 4610.

[4] ASTM, ASTM E399, Standart Test Method for Plain-Strain Fracture Toughness of Metallic Materials, Astm International, 2002.

[5] J. Schubbe, in: 25th ICAF Symp., May 2009, Springer 2009, p. 909.
[6] P. Das, R. Jayaganthan, T. Chowdhury, I.V. Singh, Mater. Sci. Forum 683, 81 (2011).

[7] J. Haigen, L. Jian, L. Zheng, T. Xianmin, in: 5th Int. Conf. Advanced Design and Manufacturing Engineering (ICADME 2015), 2015. 